\title{
A case report of co-infection of Melioidosis and cutaneous Leishmaniasis
}

\author{
Isuru Chamika Indeewara Kahandawaarachchi ${ }^{1 *}$, Gayani Samadara Premawansa', Wipula Warnasuriya', \\ Malka Dassanayake ${ }^{1}$ and Enoka Corea ${ }^{2}$
}

\begin{abstract}
Background: Leishmaniasis and melioidosis are frequently reported from the North Central Province of Sri Lanka. However, only one case of co-infection of the two diseases has been reported to date over the world. This is a case report of a patient who had co-infection with cutaneous leishmaniasis and melioidosis and was successfully treated and recovered from the illness.

Case presentation: A 61 year old female patient with diabetes mellitus presented with fever for one month's duration and was found to have hepatosplenomegaly and an ulcer over the left arm. She had elevated inflammatory markers and blood culture grew Burkholderia pseudomallei and serum was highly positive for melioidosis antibodies. A slit skin smear of the ulcer showed Leishmania amastigotes.
\end{abstract}

Conclusion: Melioidosis and leishmaniasis are emerging infectious diseases in endemic countries and can be severe. The high prevalence rates in Sri Lanka should keep the treating physicians' threshold for suspicion low for these two diseases.

Keywords: Melioidosis, Cutaneous leishmaniasis, Co-infection

\section{Background}

Melioidosis and leishmaniasis are two important emerging infectious diseases in Sri Lanka [1-3]. Both these diseases are prevalent in the North Central Province.

Melioidosis, caused by Burkholderia pseudomallei, is thought to be transmitted via inoculation of contaminated soil and less commonly via aerosol inhalation, leading to a systemic infection which may be complicated by septicemia and/or disseminated abscess formation [4].

Leishmaniasis, caused by the Leishmania parasite occurs in the forms of cutaneous, muco-cutaneous, disseminated cutaneous and systemic infection. It is transmitted by the sand-fly [5].

An extensive literature search revealed only one case report on co-infection with melioidosis and cutaneous leishmaniasis [6].

Here we report a case of co-infection of melioidosis and cutaneous leishmaniasis in a patient residing at Padaviya in the North Central Province of Sri Lanka where both diseases are prevalent.

\footnotetext{
* Correspondence: isurucik@gmail.com

${ }^{1}$ North Colombo Teaching Hospital, Ragama, Sri Lanka

Full list of author information is available at the end of the article
}

\section{Case presentation}

A 61 year old female with a history of diabetes and hypertension, from Padaviya, Sri Lanka, presented to the Colombo North Teaching Hospital with a history of fever with chills and rigors of one month's duration. She had developed an abscess over her left upper arm which ruptured into a non-healing ulcer coinciding with the onset of the fever.

On examination she was febrile and had an ulcer (Fig. 1) over her left upper arm which appeared unhealthy. Abdominal examination showed a smooth hepatomegaly $3 \mathrm{~cm}$ below the costal margin and a splenomegaly of $18 \mathrm{~cm}$. Her respiratory, cardiovascular and neurological examinations were normal.

Investigations revealed a neutrophilic leukocytosis with elevated inflammatory markers $(\mathrm{C}$ - reactive protein $149 \mathrm{mg} / \mathrm{L}$; erythrocyte sedimentation rate $-122 \mathrm{~mm}$ in first hour). The blood picture was in favor of an acute bacterial infection with neutrophils with toxic changes. Serum electrolytes, serum creatinine, and liver function tests were all normal. Her first two blood cultures did not grow any organisms but the third was positive for $B$. pseudomallei cultured in MacConkey (Fig. 2) and blood agar (Fig. 3) separately. The patient's serum was positive 


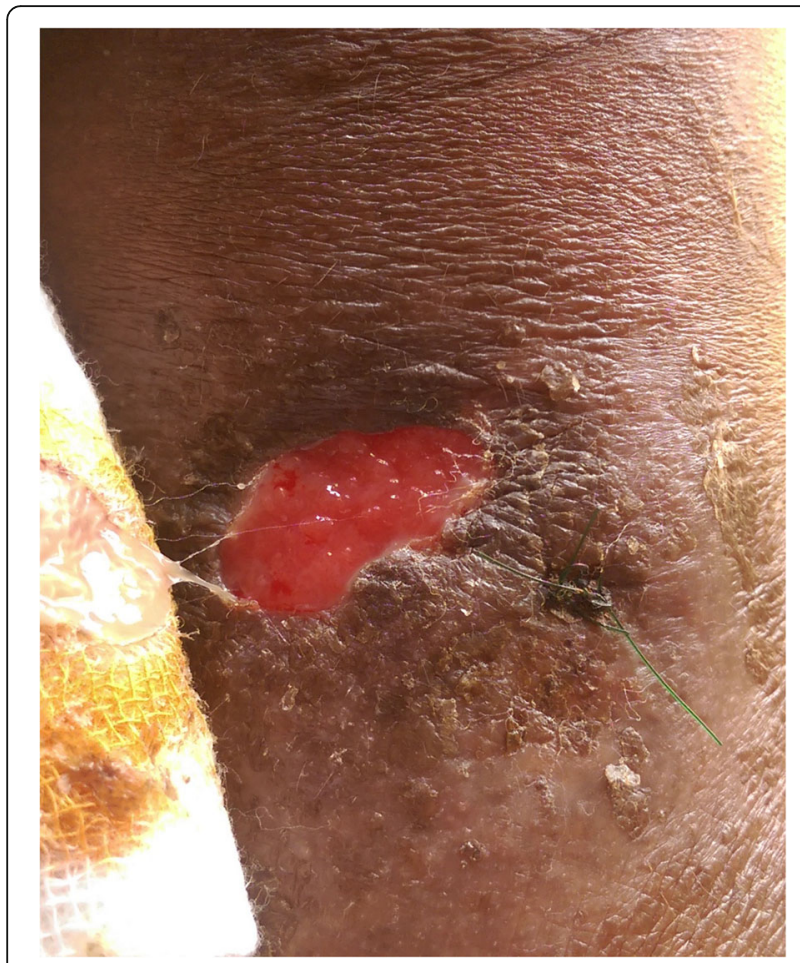

Fig. 1 Ulcer over the left arm of the patient for melioidosis antibodies by the indirect haemagglutination (IHA) test at a dilution of $>1 / 10240$ which was highly significant. The ultrasound scan and the contrast enhanced computerized tomography scan of the abdomen showed hepatosplenomegaly and mild pancreatitis but the serum amylase level was normal. There was no evidence of intra-abdominal abscesses. Fasting blood sugar level was $110 \mathrm{mg} / \mathrm{dl}$ and the capillary blood sugar levels during the hospital stay were well controlled with metformin $1 \mathrm{~g} 12$ hourly and gliclazide $40 \mathrm{mg} 12$ hourly.

Since the ulcer remained non-healing, two slit skin smears were done, both of which showed Leishmania amastigotes (Fig. 4). However, serum antibodies against the Lc-rK39 antigen (using Kalazar Detect ${ }^{\mathrm{TM}}$ kit produced by Inbios International Inc.) of the organism was negative, excluding systemic infection. Wound swab for bacterial culture showed no growth.

The patient was initially commenced on intravenous ceftazidime $2 \mathrm{~g}$ six hourly but did not respond even after five days. She developed multiple abscesses all over the body (Fig. 5) one week into the hospital admission. However, pus cultures were negative for B. pseudomallei. She was then switched to a three week course of intravenous meropenem $1 \mathrm{~g} 8$ hourly to which the fever responded. She was transferred to the Anuradhapura Teaching Hospital for continuation of meropenem for a further week and was subsequently discharged on

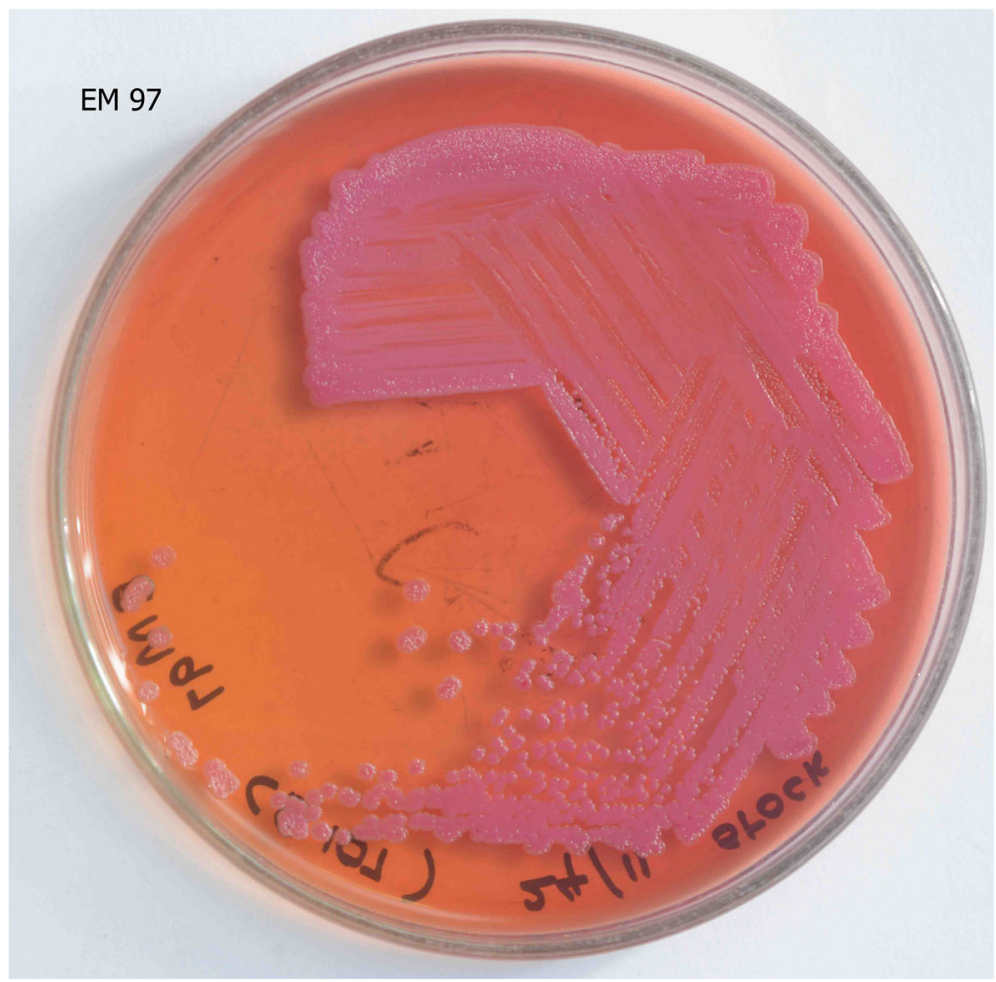

Fig. 2 B. pseudomallei cultured in MacConkey agar 


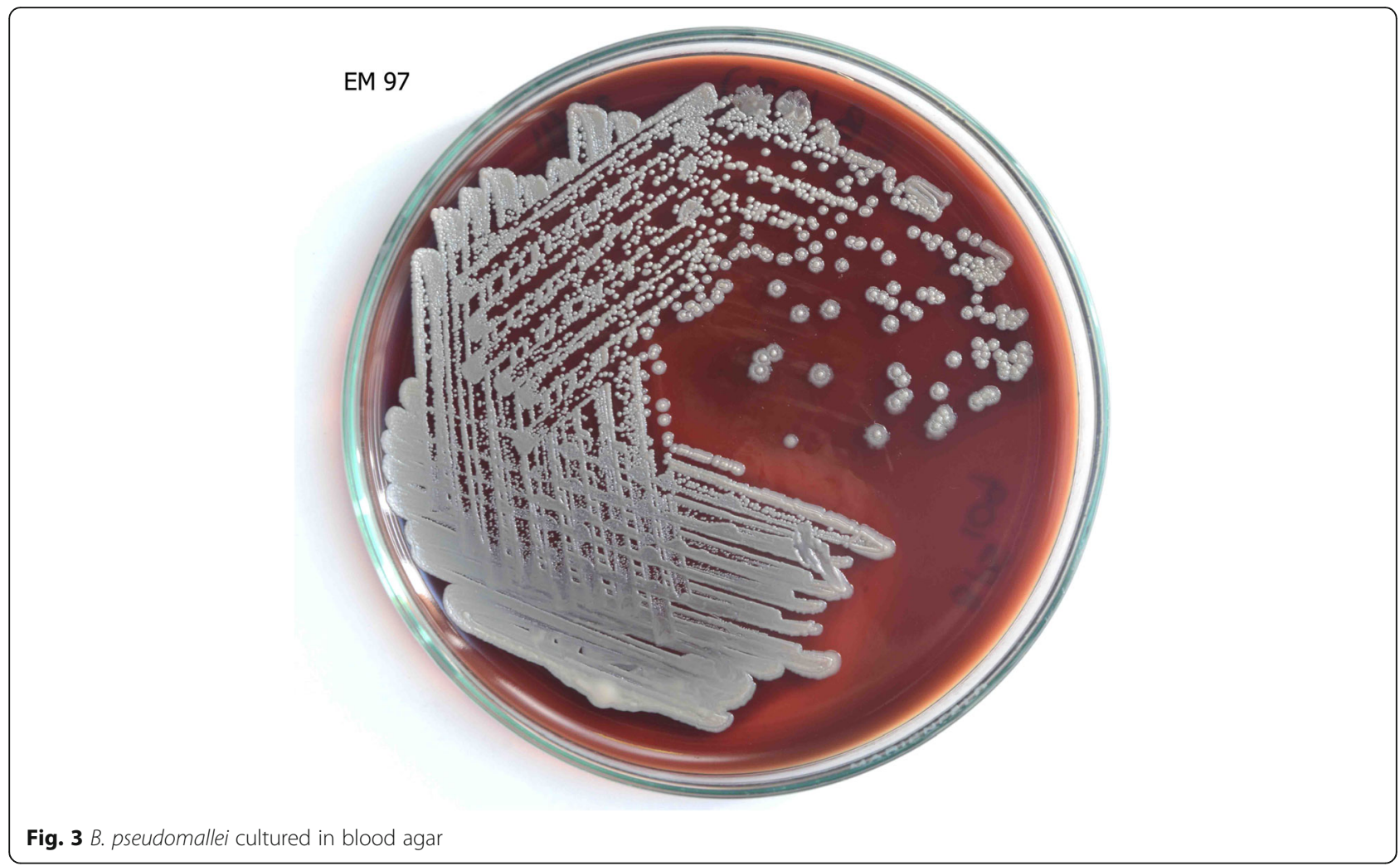

eradication therapy with oral co-trimoxazole $960 \mathrm{mg}$ (160 mg trimethoprim and $800 \mathrm{mg}$ sulfamethoxazole) 12 hourly for six months and referred to the clinic for follow up.

The skin lesion was cauterized and no further treatment was administered since it was a local infection with the Leishmania parasite. The ulcer had healed almost completely by the time of discharge.

At 3 months' follow up she remains afebrile, the ulcer healed completely and the hepatosplenomegaly absent.

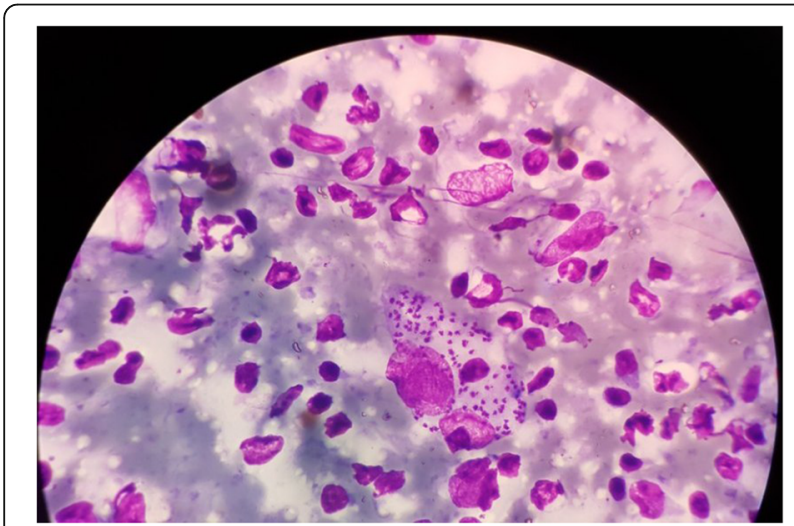

Fig. 4 Slit skin smear of the patient showing Leishmania amastigotes

\section{Discussion and conclusions}

The pathogenesis of the two illnesses has been evaluated at molecular level and certain similarities have been found. It has been shown that increased TNF- $\alpha$ levels predispose to both diseases [7] and both illnesses are acted upon by a Type $1 \mathrm{~T}$ cell response which targets intracellular pathogens [8].

The ulcer on the arm of the patient probably occurred after a bite by the sand-fly which inoculated the leishmania organism in it. Secondary contamination of the ulcer with B.pseudomallei due to the high environmental prevalence of the organism could have caused the melioidosis infection. Diabetes mellitus would have predisposed the patient to acquiring the infection as well [9].

The presence of hepatosplenomegaly in the patient initially provoked the possibility of 'kala azar' or visceral leishmaniasis but since the patient was not very ill, was antibody negative and since she recovered with antibiotics to melioidosis, this assumption was discarded later $[10,11]$.

The diagnosis of melioidosis is often elusive but can be made through antibody assays and direct isolation via cultures [12]. The positive antibody titer and culture in this patient, together, pins the diagnosis of melioidosis.

Melioidosis treatment has two arms, the intensive phase and eradication phase. During the intensive phase, ceftazidime, meropenem or imipenem is used for a duration of 2-4 weeks. Co-trimoxazole may be added if the 


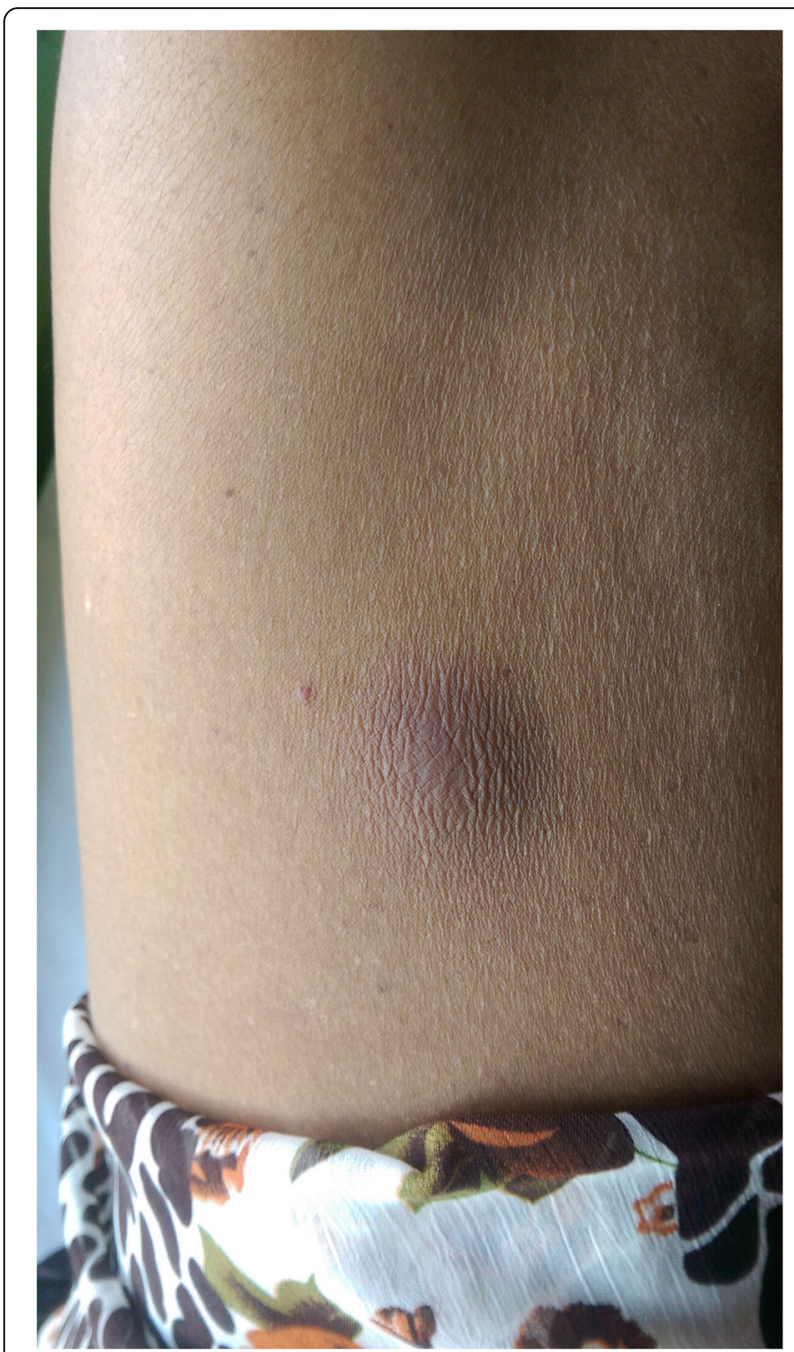

Fig. 5 Abscess over the abdomen. Multiple abscesses such as these were present in the patient

patient is poorly responding. The eradication phase uses co-trimoxazole or doxycycline up to a period of six months [13].

Cutaneous leishmaniasis can be treated with local cauterization or intra-lesional administration of sodium stibogluconate [14].

Since there was only one case report of a co-infection with both these illnesses and because there are set guidelines for the management of them individually, we treated the two infections separately.

As both melioidosis and leishmaniasis are emerging infectious diseases in Sri Lanka, physicians should have a high clinical suspicion when dealing with patients with pyrexia of unknown origin, especially when they're from areas where the diseases are more prevalent.

\section{Abbreviations}

IHA: Indirect haemagglutination; TNF-a: Tumor necrosis factor alpha

\section{Acknowledgements}

The authors would like to acknowledge the staff of the professorial unit at the Teaching Hospital, Anuradhapura, Sri Lanka for continuing treatment for the patient.

\section{Funding}

Not applicable.

\section{Availability of data and materials}

Not applicable.

\section{Authors' contributions}

Dr. ICIK: Registrar in medicine of the ward where the patient was treated. Contributed in diagnosing the disease, preparing the final manuscript and overall coordination with regard to the manuscript. Dr. GSP: Consultant physician of the ward where the patient was treated. Contributed in the clinical diagnosis of the patient's condition and doing the required referrals to confirm the diagnosis. She also composed the case history section of the manuscript. Dr. WW: Consultant Dermatologist of the hospital who confirmed the diagnosis of leishmaniasis in the patient. He also composed the components about leishmaniasis in the manuscript. Dr. MD Consultant Microbiologist of CNTH where B. pseudomallei was isolated and who contributed with the microbiological management of melioidosis in the patient. The component of melioidosis in the manuscript was carried out jointly by her and Dr. EC. Dr. EC: Consultant Microbiologist and Senior Lecturer at the University of Colombo, Sri Lanka. Contributed by performing further culture identification of B. pseudomallei and melioidosis antibody testing and composed the areas on melioidosis along with Dr. MD. All authors read and approved the final manuscript.

\section{Ethics approval and consent to participate} Not applicable.

\section{Consent for publication}

Informed written consent for publishing the patient's details including the photos, in the journal was obtained and is available for the perusal of the editors upon request.

\section{Competing interests}

The authors declare that they have no competing interests.

\section{Publisher's Note}

Springer Nature remains neutral with regard to jurisdictional claims in published maps and institutional affiliations.

\section{Author details}

${ }^{1}$ North Colombo Teaching Hospital, Ragama, Sri Lanka. ${ }^{2}$ Department of Microbiology, Faculty of Medicine, University of Colombo, Ragama, Sri Lanka.

Received: 11 April 2017 Accepted: 26 July 2017

Published online: 01 August 2017

\section{References}

1. Corea EM, Merritt AJ, Ler YH, Thevanesam V, Inglis TJ. Sri Lankan National Melioidosis Surveillance Program Uncovers a Nationwide distribution of invasive Melioidosis. Am J Trop Med Hyg. 2016;94:292-8.

2. Nawaratna SS, Weilgama DJ, Wijekoon CJ, Dissanayake M, Rajapaksha K. Cutaneous leishmaniasis. Sri Lanka Emerg Infect Dis. 2007;13:1068-70.

3. Rajapaksa US, Ihalamulla RL, Udagedera C, Karunaweera ND. Cutaneous leishmaniasis in southern Sri Lanka. Trans R Soc Trop Med Hyg. 2007;101:799-803.

4. Currie BJ, Ward L, Cheng AC. The epidemiology and clinical spectrum of melioidosis. 540 cases from the 20 year Darwin prospective study. PLoS Negl Trop Dis. 2010;4:e900.

5. Cameron MM, Acosta-Serrano A, Bern C, Boelaert M, den Boer M, Burza S, Chapman LA, Chaskopoulou A, Coleman M, Courtenay O, et al. Understanding the transmission dynamics of Leishmania donovani to provide robust evidence for interventions to eliminate visceral leishmaniasis in Bihar. India Parasit Vectors. 2016;9:25.

6. De Lajudie P, Porte L, Brygoo ER. Case of kala-azar and melioidosis observed in Indo-China. Bull Soc Pathol Exot Filiales. 1952;45:45-8. 
7. Kumar A, Short J, Parrillo JE. Genetic factors in septic shock. JAMA. 1999;282:579-81.

8. Spellberg B, Edwards JE Jr. Type 1/type 2 immunity in infectious diseases. Clinical infectious diseases : an official publication of the Infectious Diseases Society of America. 2001;32:76-102.

9. Suputtamongkol Y, Chaowagul W, Chetchotisakd P, Lertpatanasuwun N, Intaranongpai S, Ruchutrakool T, Budhsarawong D, Mootsikapun P, Wuthiekanun $\mathrm{V}$, Teerawatasook N, et al. Risk factors for melioidosis and bacteremic melioidosis. Clinical infectious diseases : an official publication of the Infectious Diseases Society of America. 1999;29:408-13.

10. Singh RK, Pandey HP, Sundar S. Visceral leishmaniasis (kala-azar): challenges ahead. Indian J Med Res. 2006;123:331-44.

11. Singh S, Sivakumar R. Recent advances in the diagnosis of leishmaniasis. J Postgrad Med. 2003;49:55-60.

12. Lau SK, Sridhar S, Ho CC, Chow WN, Lee KC, Lam CW, Yuen KY, Woo PC. Laboratory diagnosis of melioidosis: past, present and future. Exp Biol Med (Maywood). 2015;240:742-51.

13. Cheng AC. Melioidosis: advances in diagnosis and treatment. Curr Opin Infect Dis. 2010;23:554-9.

14. Aronson N, Herwaldt BL, Libman M, Pearson R, Lopez-Velez R, Weina P, Carvalho E, Ephros M, Jeronimo S, Magill A. Diagnosis and treatment of Leishmaniasis: clinical practice guidelines by the Infectious Diseases Society of America (IDSA) and the American Society of Tropical Medicine and Hygiene (ASTMH). Am J Trop Med Hyg. 2017;96:24-45.

\section{Submit your next manuscript to BioMed Central} and we will help you at every step:

- We accept pre-submission inquiries

- Our selector tool helps you to find the most relevant journal

- We provide round the clock customer support

- Convenient online submission

- Thorough peer review

- Inclusion in PubMed and all major indexing services

- Maximum visibility for your research

Submit your manuscript at www.biomedcentral.com/submit 